\title{
Craniotomy Revisited: Techniques for Improved Access and Reconstruction
}

\author{
Michael D. Cusimano and Agustinus S. Suhardja
}

\begin{abstract}
Objective: To describe simple modifications of the technique of opening and closure of the craniotomy to improve basal exposure and reconstruction. Methods: The modifications involve: a) additional soft-tissue dissection which is carried downward to the base of the ear and to the orbital rim, exposing the orbital rim and malar eminence without removing the bone; b) cutting the bone flap so that 'bridges' of bone remain that help to stabilize the flap when it is returned to the cranium at the end of the operation; c) the wedging of bone chips between the bone flap and native cranium at the time the bone is being reaffixed so as to provide firm stability by diminishing movement of the bone flap; d) the use of bone dust and bone chips mixed with the patient's blood to seal and bridge the gap between the bone flap and the native bone; e) reattachment of the temporalis muscle with the bone flap sutures. An 'inlay' technique of duraplasty is also described. Results and conclusion: These simple modifications of craniotomy provide better basal exposure and reconstruction with little additional operating time at no additional cost.
\end{abstract}

RÉSUMÉ: Nouvelle approche de la crâniotomie: techniques pour améliorer l'accès et la reconstruction. But: Décrire des modifications simples de la technique d'ouverture et de fermeture de la crâniotomie pour améliorer l'exposition basale et la reconstruction. Méthodes: Les modifications impliquent: a) une dissection supplémentaire des tissus mous qui est prolongée vers le bas jusqu'à la base de l'oreille et au bord de l'orbite, exposant le bord de l'orbite et l'éminence malaire sans retirer l'os; b) le découpage d'un volet osseux de telle sorte que des "ponts" osseux demeurent en place pour aider à stabiliser le volet quant il est remis en place à la fin de la chirurgie; c) l'implantation de fragments osseux entre le volet osseux et le crâne natif au moment où l'os est refixé afin de le stabiliser fermement en diminuant le mouvement du volet osseux; d) l'utilisation de poussière d'os et de fragments osseux mêlés au sang du patient pour sceller et remplir l'interstice entre le volet osseux et l'os natif; e) le rattachement du muscle temporal avec les sutures du volet osseux. Une technique d'"incrustation" pour la plastie de la dure-mère est également décrite. Résultats et conclusion: Ces modifications techniques simples améliorent l'exposition basale et la reconstruction tout en prolongeant peu le temps opératoire, sans augmenter les coûts de la crâniotomie.

Can. J. Neurol. Sci. 2000; 27: 44-48

The fronto-temporal craniotomy is a widely accepted component of neurosurgical practice. ${ }^{1}$ However, two problems exist with the current approach: access to the base of the skull and cosmetic deformity occuring after surgery. ${ }^{2,3,4,5}$ In general, difficulties with the access to the base of the skull have led to the development of skull-base surgery that uses approaches that avoid brain retraction. The value of these procedures in certain cases, such as extensive tumors that transgress the skull base, is beyond doubt. ${ }^{6,7}$ But the necessity for these extensive procedures for lesions that do not require such wide exposure of the cranial base is sometimes controversial. ${ }^{8,9}$ In such instances, a modification of the standard pterional approach is needed to allow increased basal exposure without extra dissection and bony work.

This paper describes and documents simple modifications of the current standard approach to fronto-temporal craniotomy that allows a focused basal approach without extra bony work. Since a problem with pterional craniotomy may be later cosmetic deformity, the second purpose of this paper is to describe a simple technique for the reconstruction of the skull defect and reapproximation of the temporalis muscle. Since a number of these problems may interfere with good outcomes from any craniotomy, these approaches may also facilitate all craniotomy techniques.

From the Division of Neurosurgery, St. Michael's Hospital, University of Toronto, Toronto, Ontario, Canada.

RECEIVED JUNE 15, 1998. ACCEPTED IN FINAL FORM JULY 12, 1999.

Reprint requests to: Michael D. Cusimano, Division of Neurosurgery, St. Michael's Hospital, 38 Shuter Street, Toronto, Ontario M5B 1A6, Canada. 


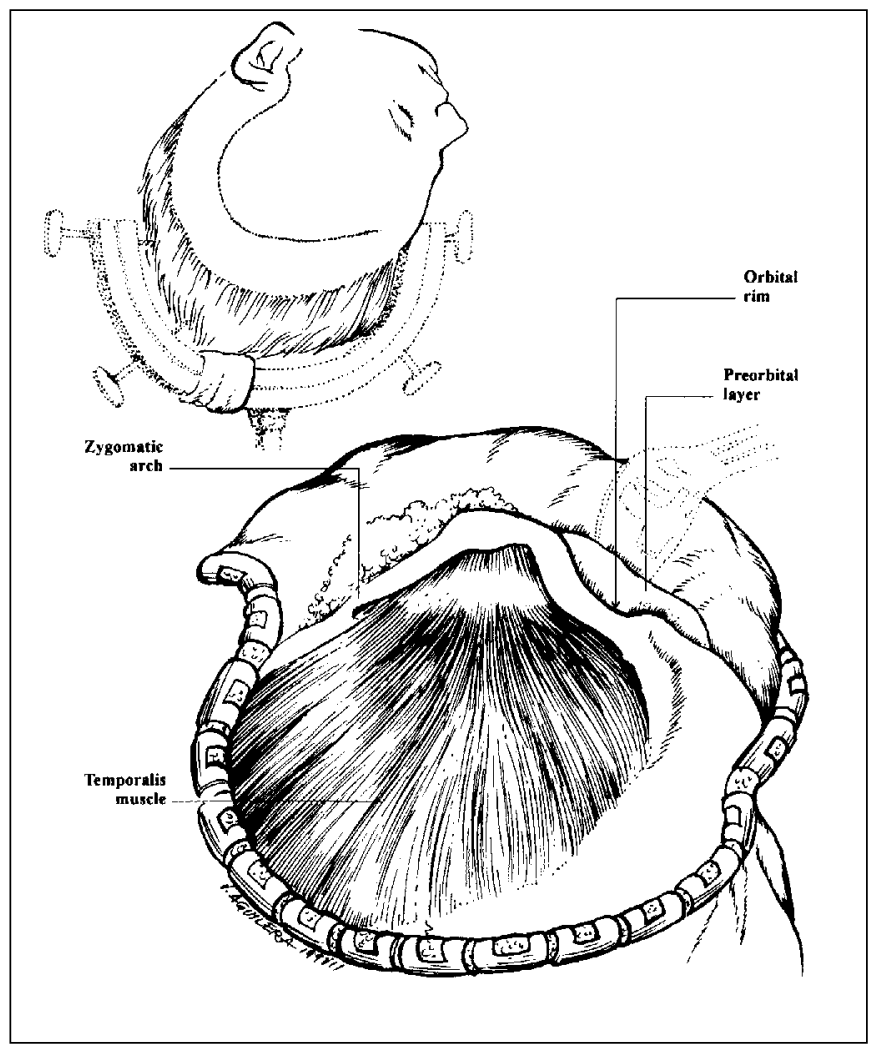

Figure 1: Soft-tissue dissection. The soft tissues are taken down so that the anteroinferior border of the superior orbital rim is clearly shown. If necessary, the zygomatic arch can also be easily shown by carrying the dissection down the orbital rim onto the zygomatic arch. This allows low frontal and low as well as anterior temporal exposure.

\section{Operative Technique}

The patient is positioned in the standard fronto-temporal position. Antiseptic precautions are followed and the scalp is injected with a mixture of $1 \%$ lidocaine and 1/100,000 epinephrine to diminish the bleeding from the skin edges and to minimize the need for transfusion.

The scalp is incised down to the pericranium where there is no underlying temporalis muscle and down to the superficial temporalis fascia over the temporalis muscle. Electrocautery is then used to cut through the pericranium to the free surface of the bone. With a wide periosteal elevator, the periosteum is stripped free of the bone and kept with the scalp. At the superior temporal line, this soft-tissue dissection is continued to include the most superficial layer of soft tissue that overlies the temporalis muscle. The dissection is carried forward until the surgeon can just palpate the keyhole position and note that the soft-tissue dissection has advanced far enough. At this point the surgeon will begin to observe the triangular fat pad of the temporalis muscle and does an interfascial approach to preserve the frontalis branch of the facial nerve, as described by Yasargil ${ }^{10}$ and Yasargil et al. ${ }^{11}$ The widespread practice is to stop the soft-tissue dissection at this level.

Our modified procedure involves taking the soft tissue down even further. The soft tissues are taken down so that the antero-

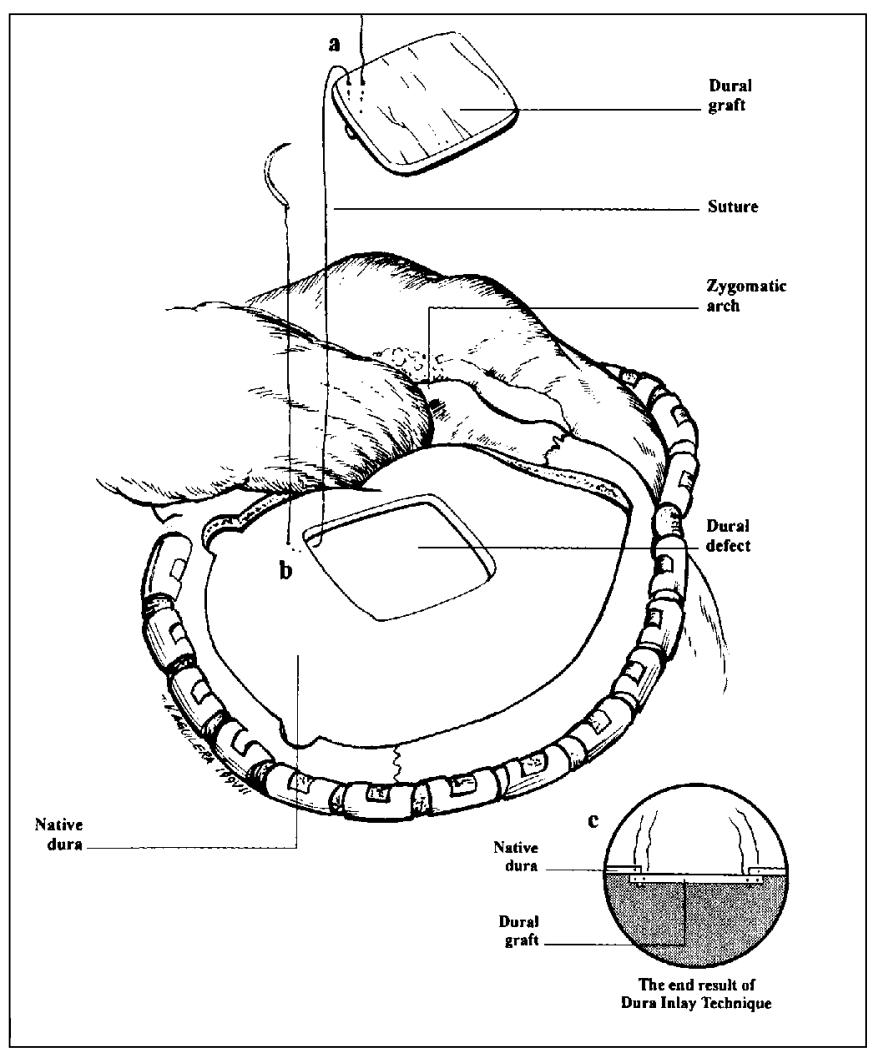

Figure 2: The inlay dural technique. (a) The suture is passed from one side of the dural graft to the other; the suture is passed to the original side of the dural graft. (b) The suture is passed from the inner part to the outer part of the native dura. (c) The end result of the dural-inlay technique.

inferior border of the superior orbital rim is identified and freed completely (Figure 1). This is carried forward along the deep layer of the temporalis fascia which is continuous with the periosteal layer overlying the orbital rim. We have found that it is not necessary to dissect the full periorbita. With the use of the wide periosteal elevator, the plane of soft tissues over the orbital rim is carried down to its junction with the zygoma. If lowtemporal exposure is necessary, the plane is carried forward and posteriorly over the zygomatic arch as well. Once the scalp has been turned, the bony structures of the orbital rim and zygomatic arch are fully exposed. If further exposure is necessary, the incision anterior to the tragus is carried down to the base of the ear, and the masseteric fascia is elevated further. With the assistance of a right-angle retractor, this procedure exposes the malar eminence.

The essential feature here is that the soft tissues are dissected to expose the bony structures, but the bones are not necessarily removed. If a full skull-base approach is not necessary, the structure of the orbit and zygomatic arch are left intact. In this instance, we have named the exposure, the semiskull-base approach.

Next, the surgeon elevates the temporalis muscle from its anterior aspect in the temporalis fossa, stripping it free of the bone directly. In other descriptions ${ }^{12}$ of this procedure, a small piece of muscle is often left behind and the denervated piece of 


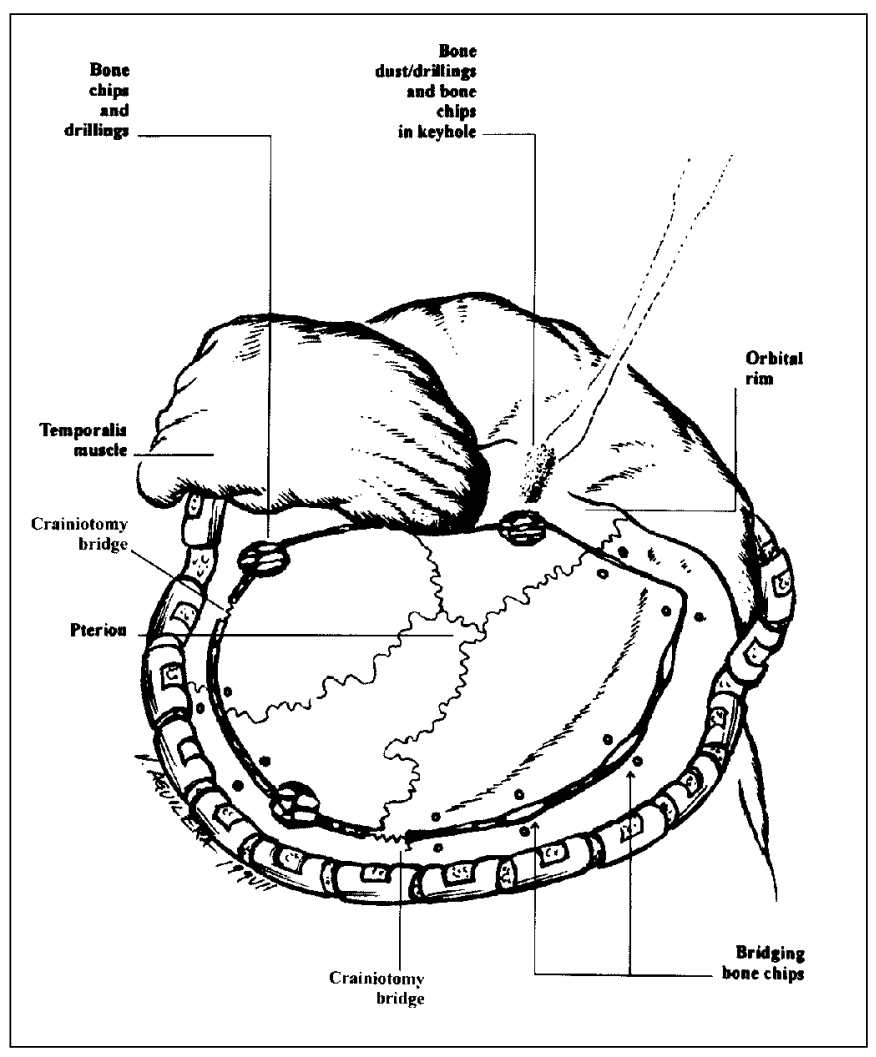

Figure 3: Reconstruction of the bone flap. Bony defects are filled with bone chips and covered with bone dust that is mixed with the patient's blood. Bone chips bridging the craniotomy also add further stability to the bone flap.

muscle atrophies in later stages, which leads to further cosmetic deformity. We have found that the full vascularized muscle must be evacuated from this location and that it is essential to maintain the vascularity of the temporalis muscle. Needless coagulation in the infratemporal fossa must be strictly avoided to prevent devascularization or denervation of the muscle.

The temporalis muscle is incised along the superior temporal line. Unlike other procedures, ${ }^{12}$ ours leaves no residual temporalis fascia on the superior temporal line. We have found that this piece of fascia desiccates during the operation and has no strength to hold the sutures used to reapproximate the temporalis muscle at the end of the procedure. The temporalis muscle is freed completely and then reflected inferiorly, as is standard practice. ${ }^{10}$

A craniotomy can then be fashioned. After placement of the burr holes, the craniotome is passed from one bur hole to the next without completely joining the cut in the bone to the next hole. A small "bridge" of several millimeters of bone is left in place and the craniotome is removed in reverse direction back to the bur hole through which it was originally placed. At the time that the craniotomy is elevated, the bridges are sequentially "cracked" by gentle upward elevation of the flap after freeing the dura. This technique can be used with a single or multiple bur hole bone flap. Drillings of bone from the burr hole or from the high-speed drill are saved. Any bone that must be rongeured

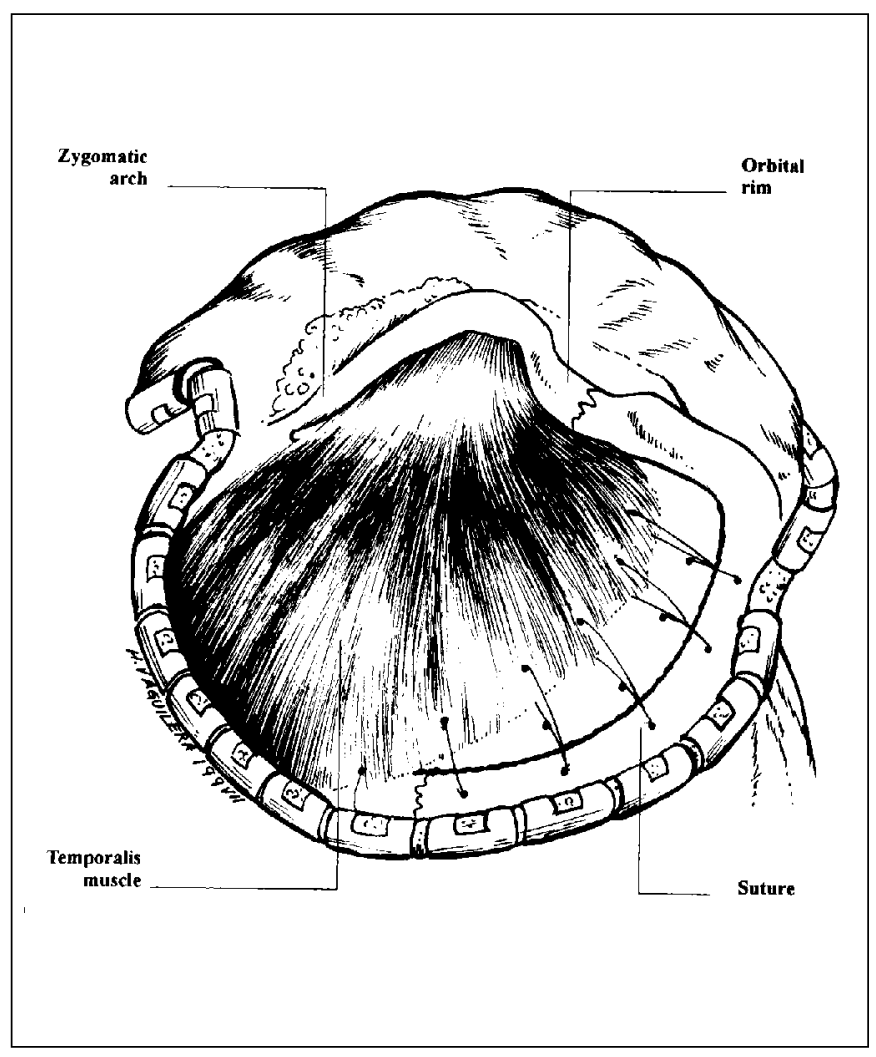

Figure 4: Reconstruction of the temporalis muscle. The sutures holding the bone flap are passed through the temporalis muscle and its fascia, and the muscle is repositioned in its original anatomical position.

from the pterion is also preserved for the reconstruction. If an orbital-cranial or orbital-craniozygomatic osteotomy is necessary, the bone of the greater wing of the sphenoid in the pterion is left in place, and the osteotomies proceed according to standard practice. ${ }^{9}$

This low exposure that results from the extensive soft-tissue dissection now allows the craniotomy cuts, particularly in the frontal region, to be at least a centimeter lower than they would otherwise have been without the soft-tissue dissection. This gives the surgeon the extra exposure often needed for lesions that approach the skull base but do not require the full exposure of the skull base, through, for example, an orbitozygomatic osteotomy.

If a dural graft is necessary, it is sutured to the native dura with an inlay technique similar to that described by Guity and Young $^{13}$ (Figure 2).

Either on cranial opening or once the cranial procedure is completed, holes for the reapproximation of the bone are made for the sutures. Heavy, nonabsorbable sutures are used to securely reapproximate the craniotomy bone flap to the native cranium in at least five or more places, where possible, around the circumference of the flap. Cutting the bone flap so that 'bridges' of bone remain helps to stabilize the flap when it is returned to the cranium at the end of the operation. To further stabilize the flap, small chips of bone wedged into the craniotome gap have been used to support the flap with excellent 


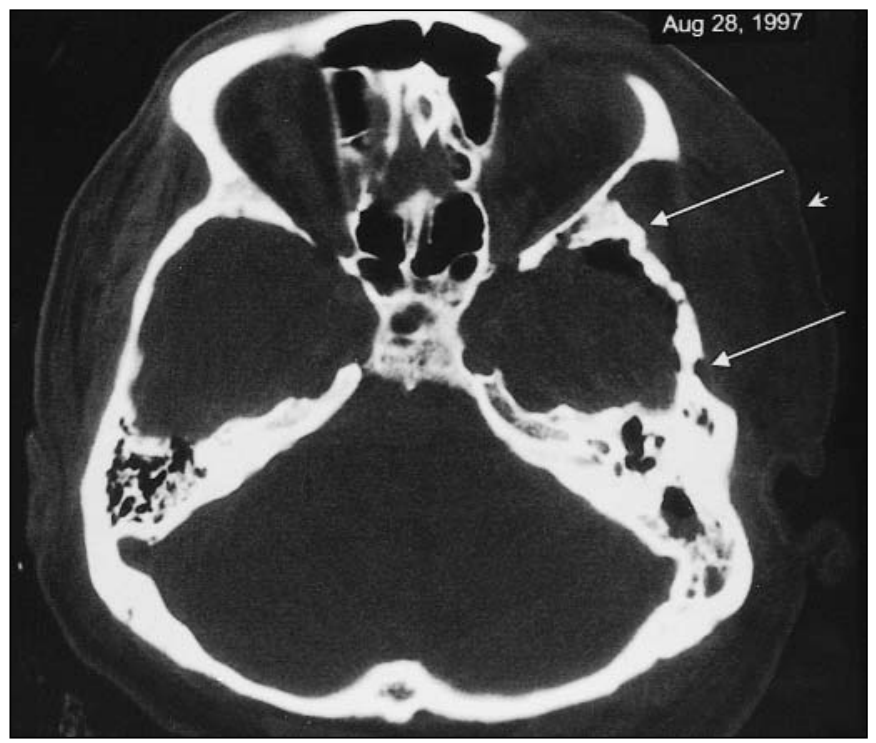

Figure 5: Transverse view of the non-contrast computed tomography scan of the head of a patient with previous left modified fronto-temporal craniotomy at six month follow-up, shows the fusion of the bone flap and the native bone (long arrow). Note also that there is no depression in the temporalis fossa (short arrow).

results to give it long-term stability. These small bony grafts have been placed at the site of the sutures to prevent them from migrating. Bony defects are then filled with bone chips and covered with bone dust that is mixed with the patient's blood to create a slurry of osteoblastic cement to aid in the reconstruction (Figure 3).

The temporalis muscle is then reconstructed. Sutures used to secure the bone flap are left intact: the ends are not cut. The free ends of the sutures of the craniotomy are threaded with the native needles still attached or through standard French-eye needles (Anchor Products Company, Addison, IL). The sutures holding the bone flap are then passed through the temporalis muscle and its fascia, and the muscle is repositioned in its normal anatomical position (Figure 4). If only a part of the temporalis muscle has been mobilized for the craniotomy, the posterior part of the muscle is reapproximated to the free edge of the muscle and fascia with sutures and not to the bone stitches posteriorly.

\section{Discussion}

Cosmetic defect after craniotomy, an issue long neglected by many neurosurgeons, can cause physiological discomfort to patients and affect the overall surgical outcome. ${ }^{2}$ Disfigurements are most commonly caused by bone-flap depression, asymmetry of the temporalis muscle, or a combination of the two. ${ }^{2,3,4,5}$ Boneflap fixation is an important part of the reconstruction in a craniotomy. The sinking of a replaced bone flap not only causes a cosmetic deformity, ${ }^{4}$ but can also cause a functional disturbance in the brain, such as constructional apraxia. ${ }^{14}$ The bone flap is usually fixed by sutures to the native bone with either nonabsorbable suture material or wires, ${ }^{15}$ or fixed with a microplate. ${ }^{16}$ We have not found wire or microplates superior to nonabsorbable sutures as long as the sutures are properly and tightly secured and placed around the circumference of the flap. Although wire or non-absorbable sutures avoid the high cost of microplates and provide immediate stability, the replaced bone flap may still sink over time, leading to cosmetic and possible functional deficits. This sinking is likely due to the continued presence of a gap between the bone flap and the native bone. Although many surgeons fill the burr holes of a craniotomy with bone dust at the end of a procedure, our modification calls for the cutting of the flap to leave small bridges of bone between the craniotomy flap and the native cranium. It also allows the placement of bone chips in the gap between the bone flap and native cranium and then securing the bone flap with appropriate sutures. The gap between the bone flap and the native bone is, therefore, effectively "bridged" by the bone chips and effectively make the bone flap and native bone a single unit. This bridge connects the bone flap with the native bone and often provides long-term stability (see Figure 5).

The use of bone chips as a bridge to help stabilize the flap is analogous to the bridged-craniotomy technique that Ochiai et al. ${ }^{4}$ describe. A bridged craniotomy requires the use of a narrowgauge craniotome alternated with a regular craniotome to create a series of bridges between the flap and the cranium. The technique is complicated, requires extra instruments, and considerably lengthens the operation, but effectively provides more stability. Our method of bridging the bone flap to the cranium by cracking the bone and by bridging with bone chips and drillings preserved during the craniotomy exposure provides equivalent stability without requiring additional time or equipment. Our use of the patient's own blood mixed with bone dust to form a slurry of osteoblastic cement obviates the need for synthetic materials, either for mixing with the bone dust ${ }^{17,18}$ or for covering the burr-hole site. ${ }^{19}$ In addition, our technique eliminates the problems of other methods: foreign-body reactions, ${ }^{20,21,22}$ cost, and interference with imaging studies. ${ }^{23}$

Another common cause of cosmetic defects after craniotomy is the asymmetry of the temporalis muscle. ${ }^{2,3,5}$ One of the causes of temporalis-muscle asymmetry is the malposition of the muscle. A number of methods of reconstruction of the temporalis muscle in its original position have been described. ${ }^{24,25,26,27}$

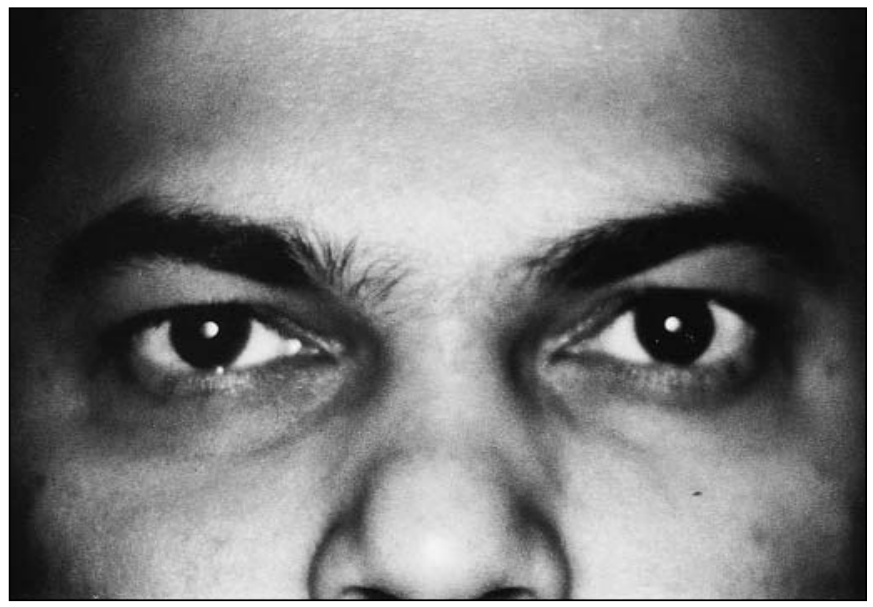

Figure 6: Frontal picture of a patient at six-month follow-up with previous fronto-temporal craniotomy showed minimal temporal depression. 
Zager et al. ${ }^{27}$ and Verlooy, ${ }^{26}$ for example, fix the temporalis muscle to a microplate. Even though microplates provide a firm fixation of the bone and are especially useful for a small craniotomy below the temporal line, they have not gained widespread acceptance, possibly because of the additional cost and the imaging artifact that they produce. Stechison ${ }^{25}$ and Day et al. ${ }^{24}$ drill a series of bone channels along the superior temporal line as places to reattach the temporalis muscle. Their technique is simple and requires no additional devices, but it does require that additional holes be made in the skull. Our technique, which includes reattachment of the temporalis muscle with the bone flap suture is simple and requires no additional holes in the skull to be made and needs no additional device. This simple technique of attachment of the temporalis muscle to the bone flap sutures provides immediate and long term firm attachment of the temporalis muscle and prevents temporalis depression (Figure 6.).

These simple modifications of craniotomy technique provide better basal exposure and approximation to the original anatomical configurations with little additional operating time at no additional cost.

\section{ACKNOWLedgment}

This paper was prepared with the assistance of Editorial Services, The Hospital for Sick Children, Toronto, Ontario, Canada. We also thank Professor Anne Agur, Dr. Stefan Konasiewicz, and Jackie Grummitt for their helpful commentary and assistance in the preparation of the manuscript.

\section{REFERENCES}

1. Yasargil MG. Reconstructive and constructive surgery of the cerebral arteries in man: Part C. Aneurysm, arteriovenous malformation and fistulae. In: Yasargil MG, ed. Microsurgery Applied to Neurosurgery. Stuttgart: George Thieme Verlag, 1969: 119-150.

2. Badie B. Cosmetic reconstruction of temporal defect following pterional craniotomy. Surg Neurol 1996; 45: 383-384.

3. Lacey M, Antonyshyn O, MacGregor JH. Temporal contour deformity after coronal flap elevation: an anatomical study. J Craniofac Surg 1994; 5: 223-227.

4. Ochiai C, Okuhata S, Yoshimoto Y, et al. Bridge craniotomy for stable fixation of a bone flap. Technical note. J Neurosurg 1996; 85: 518-519.

5. Persing JA, Mayer PL, Spinelli VM, et al. Prevention of "temporal hollowing" after fronto-orbital advancement for craniosynostosis. J Craniofac Surg 1994; 5: 271-274.

6. O'Malley Jr BW, Janecka IP. Evolution of outcomes in cranial base surgery. Semin Surg Oncol 1995; 11: 221-227.

7. Persing J. Cranial base surgery: an overview. J Craniofac Surg 1995; 6: $2-3$.

8. Ojemann RG. Skull base surgery: a perspective. J Neurosurg 1992; 76: 569-570.
9. Samii M, Tatagiba M, Monteiro ML. Meningioma involving the parasellar region. Acta Neurochir Suppl (Wien) 1996; 65: 63-65.

10. Yasargil MG. Operative approach: interfascial pterional (frontotemporosphenoidal ) craniotomy. In: Yasargil MG, ed. Microneurosurgery. I. Microsurgical Anatomy of the Basal Cisterns and Vessels of the Brain, Diagnostic Studies, General Operative Techniques and Pathological Considerations of the Intracranial Aneurysms. Stuttgart: George Thieme Verlag, 1984: 215-233.

11. Yasargil MG, Reichman MV, Kubik S. Preservation of the frontotemporal branch of the facial nerve using interfascial temporalis flap for pterional craniotomy. Technical note. J Neurosurg 1987; 67: 463-466.

12. Spetzler RF, Lee KS. Reconstruction of the temporalis muscle for pterional craniotomy. Technical note. J Neurosurg 1990; 73: 636-637.

13. Guity A, Young PH. A new technique for closure of the dura following transsphenoidal and transclival operation. Technical note. J Neurosurg 1990; 72: 824-828.

14. Rengachary SS, Amini J, Batnitzky S. Reversible constructional apraxia from a floating bone flap. Neurosurgery 1979; 5: 365-367.

15. Ciric IS, Rosenblatt S. Supratentorial craniotomies. In: Apuzzo MLJ, ed. Brain Surgery, Vol 1. New York: Churchill Livingstone, 1993: 51-70.

16. Couldwell WT, Fukushima T. Cosmetic mastoidectomy for the combined supra/infratentorial transtemporal approach. Technical note. J Neurosurg 1993; 79: 460-461.

17. Symon L, Pell MF. Cerebrospinal fluid rhinorrhea following acoustic neurinoma surgery. Technical note. J Neurosurg 1991; 74: $152-153$.

18. Tsuchimochi $\mathrm{H}$, Nagasaka $\mathrm{S}$, Yamada $\mathrm{H}$, et al. Cosmetic cranioplasty using the bone chips and biobond (EDH-adhesive). Technical note. No Shinkei Geka 1989; 17: 457-459.

19. Rhoton Jr AL. Anatomy of saccular aneurysms. Surg Neurol 1980; 14: 59-66.

20. Horowitz SM, Purdon MA. Mechanisms of cellular recruitment in aseptic loosening of prosthetic joint implants. Calcif Tissue Int 1995; 57: 301-305.

21. Pollice PF, Silverton SF, Horowitz SM. Polymethylmethacrylatestimulated macrophages increase rat osteoclast precursor recruitment through their effect on osteoblast in vitro. J Orthop Res 1995; 13: 325-334.

22. Quinn J, Joyner C, Triffitt JT, et al. Polymethylmethacrylateinduced inflammatory macrophages resorb bone. J Bone Joint Surg Br 1992; 74: 652-658.

23. Hillers TK, Roseland AM, Giller CA. Transcranial Doppler penetrance of methyl methacrylate: technical note. Acta Neurochir (Wien) 1995; 133: 93-94.

24. Day JD, Levy M, Fukushima T. Temporal muscle fixation. J Neurosurg 1995; 82: 701. (Letter)

25. Stechison MT. Temporal muscle fixation. J Neurosurg 1995; 82: 701. (Letter)

26. Verlooy J. Temporal muscle fixation. J Neurosurg 1994; 80: 1132. (Letter)

27. Zager EL, DelVecchio DA, Bartlett SP. Temporal muscle microfixation in pterional craniotomies. Technical note. J Neurosurg 1993; 79: 946-947. 